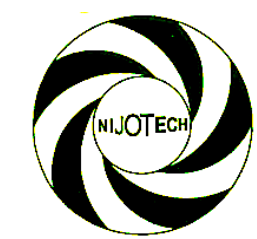

Nigerian Journal of Technology (NIJOTECH)

Vol. 39, No. 1, January 2020, pp. 36 - 41

Copyright@ Faculty of Engineering, University of Nigeria, Nsukka

Print ISSN: 0331-8443, Electronic ISSN: 2467-8821 www.nijotech.com

http://dx.doi.org/10.4314/njt.v39i1.4

\title{
EFFECTIVENESS OF GEOPHYSICAL ASSESSMENT OF BOREHOLES DRILLED IN BASEMENT COMPLEX TERRAIN AT AFE BABALOLA UNIVERSITY, USING ELECTROMAGNETIC (E.M.) METHOD
}

\author{
S. O. Oyegoke ${ }^{1}$, O. O. Ayeni ${ }^{2}$, K. O. Olowe ${ }^{3, *}$, A. S. Adebanjo ${ }^{4}$ and O. O. Fayomi ${ }^{5}$ \\ $\mathbf{1 , 2 , 3 , 4 , 5}$, DePARTMENT OF CIVIL ENGINEERING, AfE BABAlola UniVERSITY Ado EKITI, EKITI STATE, NIGERIA \\ E-mail addresses: ${ }^{1}$ soyegoke@yahoo.com, 2adebanjo.as@abuad.edu.ng, \\ 3fayomilamide@yahoo.com
}

\begin{abstract}
In this research, an Electromagnetic (E.M) method of groundwater investigations was used as an on-spot assessment tool to test the integrity of the developed borehole in Afe Babalola University, Ado-Ekiti. Some randomly selected functional and abandoned boreholes developed by the Vertical Electrical Sounding (VES) methods were chosen for this study, with the aim to know the potential of the boreholes. Four transverses were established across the institution consisting of two functional and two abandoned boreholes selected from the existing forty boreholes. These were subjected to E.M method of groundwater investigation using a PQWT S500 series machines. The results obtained from this study produced curve graphs and subsurface profile maps of each transverse location. It was observed that boreholes TR 1 and TR 3, were accurately sited on vertical fractures and weathered formations while TR 2 and TR 4 were wrongly sited at the locations of poor groundwater yielding zone.
\end{abstract}

Keywords: Electromagnetic, Vertical electrical Sounding, transverse, Groundwater.

\section{INTRODUCTION}

A safe, reliable, and easily accessible water supply is essential for good health. For several decades, about a billion people in developing countries have not had a safe and sustainable water supply. It has been estimated that a minimum of 100 liters of water per person per day is required in the home to ensure all personal hygiene, food hygiene, domestic cleaning, and laundry needs [1]. This domestic water consumption is dwarfed by the demands of agriculture and ecosystems, even in wealthy countries where per capita domestic water consumption greatly exceeds this value [2]. To cover all these requirements and to avoid water stress, experts generally agreed that about 1,000 cubic meters of fresh water per capita per year are needed. Many of the inhabitants of the developing countries do not have access to potable water and mostly drink from sources that are often polluted and unreliable, resulting in the prevalence of water borne diseases. The need for alternative water supply systems puts groundwater as the most viable source of potable water supply.

The detailed hydrogeological study is significant and is considered a priority in many groundwater exploration programs. Many geophysical methods have been used for groundwater prospecting. Though, the most widely used method is the electrical resistivity (ER) method. It is a well-known geophysical method that has been used in groundwater exploration and contaminant delineation in many countries with varying degrees of success as discussed in the literature [3-5]. In some cases, the method has produced good borehole drilling results, especially in granitic environments. Other geophysical methods have gained favour in the groundwater sector, though not widely used in Nigeria. One such is the electromagnetic (EM) methods. These methods have either been used exclusively or in combination with the ER method [68]. Though varying degrees of success have been achieved with the EM method, comprehensive

* Corresponding author, tel: +234806 6363348 
interpretation of data is absent in previous applications. Detailed interpretation of geophysical data is useful for effective delineation of groundwater-bearing zones or features.

Electrical Resistivity Method of geophysical survey utilizing different electrode arrays such as, Wenner, Schlumberger, dipole- dipole, pole-dipole, etc. had been used as predominant tool for groundwater delineation in the Precambrian basement complex of Afe Babalola University, Ado. The results of the geophysical investigations had resulted into site selection and drilling of an estimated numbers of forty (40) boreholes to cater for the water supply needs of the growing population of the university. The boreholes were critically examined and it was however observed that twenty-five (25) are operating at moderate yield capacity, while an estimated Fifteen (15) boreholes, were either abandoned or operating at very poor performance. From the pool of drilled boreholes within the institution, Four (4) boreholes consisting of two (2) functional and two (2) abandoned were randomly selected and subjected to groundwater investigation using the Electromagnetic (E.M) method with the aid of PQWT S-500 series machines. Thus, an Electromagnetic (E.M) method of groundwater investigations was used as an on-thespot assessment tool to test the integrity of the choice of boreholes considering some randomly selected functional and abandoned boreholes in the study area.

\section{DESCRIPTION OF THE STUDY AREA}

Afe Babalola University, Ado Ekiti (ABUAD), a Federal Government-licensed Private university is located in
Ado-Ekiti along Ijan road, opposite The Federal Polytechnics, Ado Ekiti as presented in Fig. 1. The institution has an estimated total population of 11,100 ; that is students population of 8,850 and Administrative staff (Teaching and Non-Teaching) of 2,255 . The terrain of the study area is gently undulating, with topographic elevation ranging from $300 \mathrm{~m}$ to $370 \mathrm{~m}$ above sea level. Ado Ekiti is underlain by crystalline rocks made of older granite, Migmatite and Charnockites with little or no fracture in most location and shallow overburden.

\subsection{Geology and Hydrogeology of the Study Area}

The geology of ABUAD belongs to the basement complex, igneous rock, rock of South-Western, Nigeria. The lithiological rock units are basically crystalline basement rocks which include coarse grained charnokite (the most abundant in Ado Ekiti), fine grained granite, medium grained granite and porphyritic biotite, medium grained granite and quartzite. $A B \cup A D$, experiences a tropical climate with distinct wet and dry seasons.

These seasons are associated with the prevalence of maritime south westerly monsoon winds from the Atlantic Ocean and the dry continental north easterly harmattan winds from the Sahara Desert. The community therefore enjoys rainwater surplus between May and October with substantial rainwater deficit between November and April.

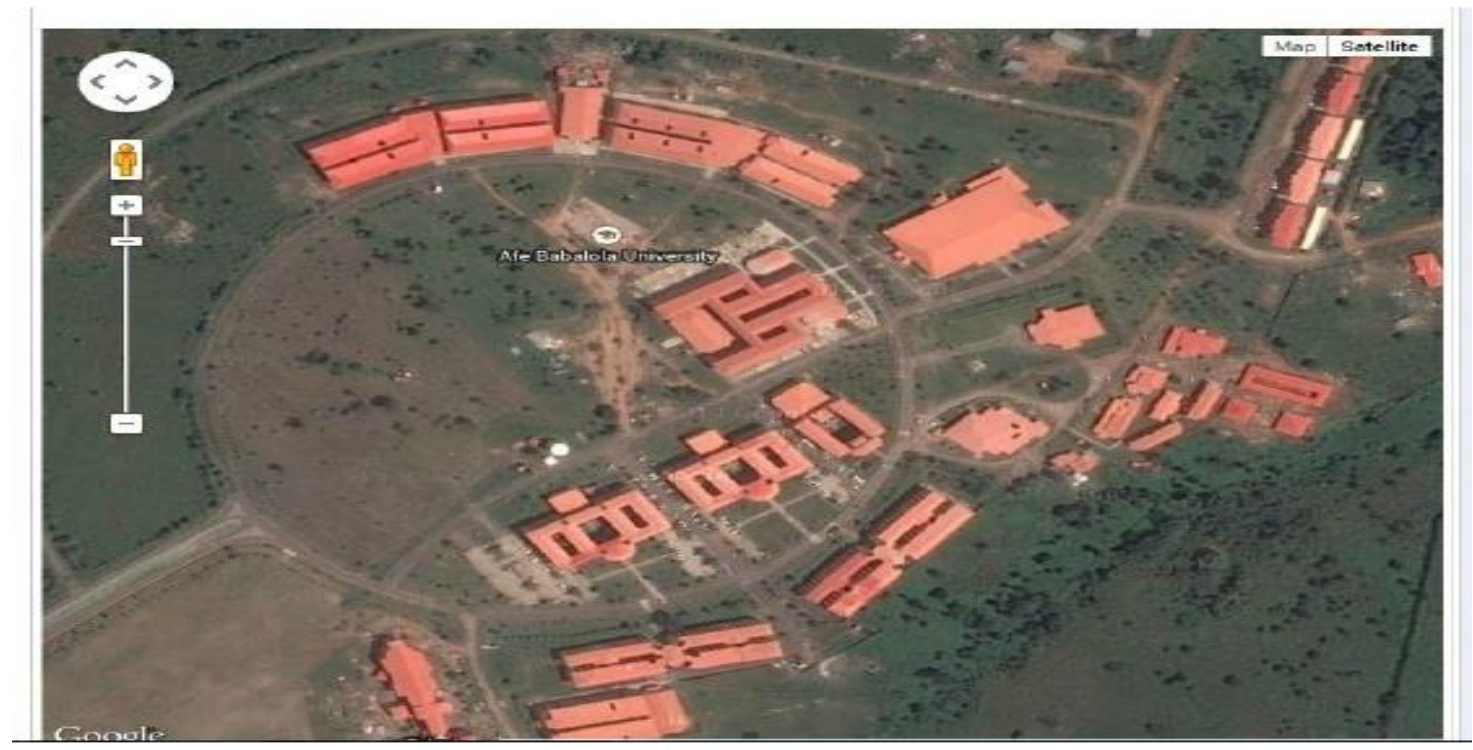

Fig. 1: Map of the Study Area. 
Hydro geologically, like in other typical basement complex terrain, unweathered or freshcrystalline rocks have hardly any potential in terms of groundwater occurrence and flow. However, the mode of groundwater occurrence in the study area is through the development of secondary porosities or permeabilities as a result of fracturing, jointing, shearing and deep weathering. The fractures might have probably developed from transpressive forces during tectonic movement, pressure relief due to erosion of overburden rock, shrinking during cooling of the rock mass and the compression and tensional forces caused by regional tectonic stresses.

\section{METHODOLOGY}

A total number of four (4) transverses were established across the university campus, each transverse bearing the locations of the existing four boreholes as shown in Fig. 2. Two functional and two abandoned boreholes that were randomly selected from the pool of boreholes spread across the institution were selected for this study. TR1 represents borehole along obasanjo way, TR2 represents borehole at the local kitchen, TR3 indicates borehole at the Post-Graduate school and TR4 represents borehole at the Staff Quarter, Block K. The E.M machine (PQWT) was set up at each selected boreholes, whereby the borehole is at $10 \mathrm{~m}$ marked on the ground. E.M electrode probe $\mathrm{M}$ and $\mathrm{N}$ are placed on the ground at point 0 and $10 \mathrm{~m}$ along the tranverse, the probes are connected to the E.M console via cable which reads the electromagnetic impulse generated by those points, the $\mathrm{M}$ and $\mathrm{N}$ electrode as presented in Fig. 3 are moved $1 \mathrm{~m}$ to the right and side of the measured line, that is $M$ is moved to $1 m$, while $N$ is move to $11 \mathrm{~m}$, readings are taking, this continues until the entire length is covered, the machine at a push of a button, automatically generate the curve graphs and profile map of the entire measured points.

\section{RESULTS AND DISCUSSIONS}

This section presents the data analysis and interpretation of the results obtained from the Electromagnetic machine. The E.M machines automatically generated the subsurface profile mapping of each transverse location from which deductions were made. The results are presented below.

Based on the subsurface profile map presented in Fig. 4 , it was observed that there are viable weathered zones with visible vertical fractured in the locations 5 , 10 and $11 \mathrm{~m}$ exceeding a penetration depth of $100 \mathrm{~m}$ below the surface cutting across the horizontal measured point at the existing transverse.

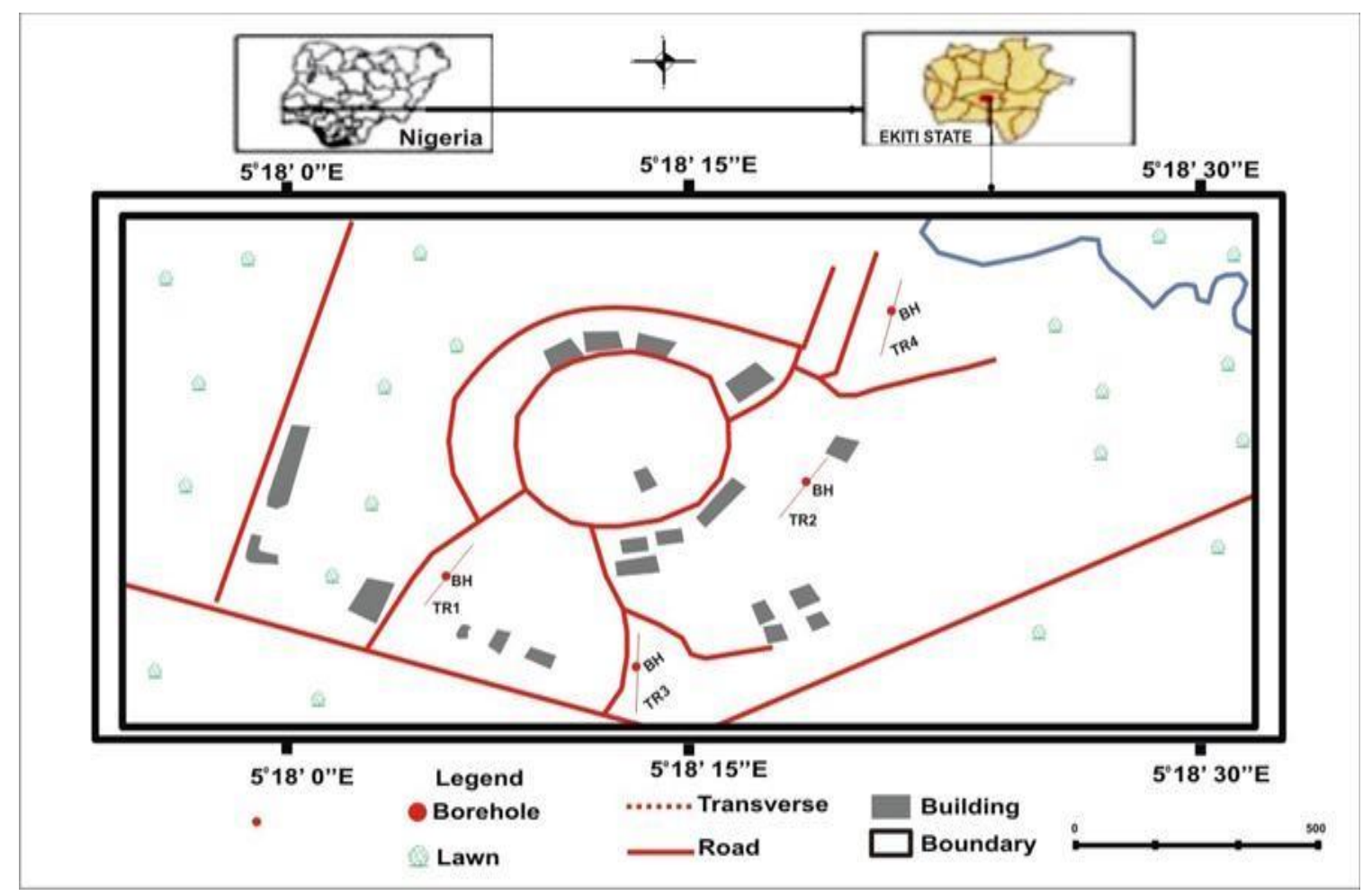

Fig. 2: Map of Afe Babalola University indicating locations of the Boreholes examined 


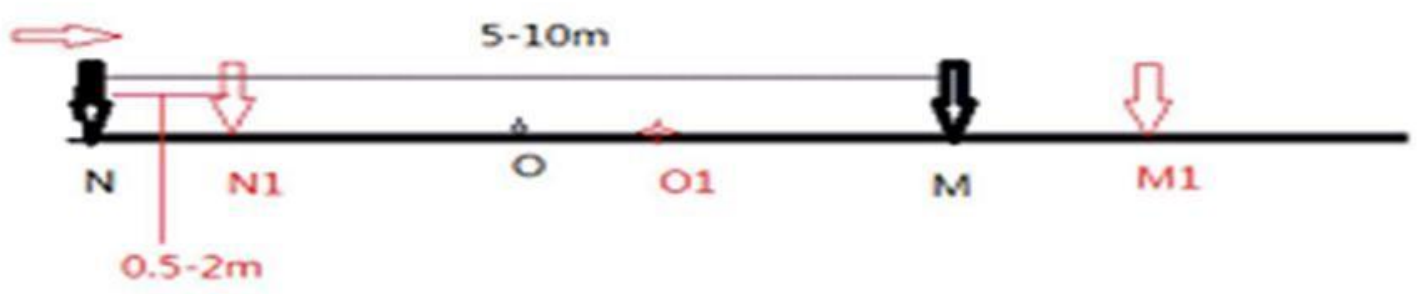

Fig. 3: Typical movement of $M$ and $N$ Electrode along a measured line

The examined borehole was accurately sited on one of the vertical fractures at $10 \mathrm{~m}$ along the transverse. The Existing borehole was sited at the $10 \mathrm{~m}$ along the horizontal measured point.

From Fig. 5 the subsurface profile map, indicates that the geologic formation below the surface of the transverse investigated does not support a substantive groundwater accumulation, but a choice for shallow well. Hence, such a location should not have been considered for siting of the borehole for groundwater exploitation. The existing borehole was sited at the $10 \mathrm{~m}$ along the horizontal measured point. The result obtained from the subsurface profile map shown in Fig. 6 indicates that the subsurface geological formation support groundwater accumulation and transmissivity, while the borehole was sited at $10 \mathrm{~m}$ point along the horizontal Axis.

It is observed that there are two potential hexagon shaped fractured points that imply good locations for groundwater exploitation, which should have been exploited. The existing borehole is cited at the $10 \mathrm{~m}$ along the horizontal measured point.

Results from Fig. 7 of the subsurface map indicates that the geologic formation has two potential locations at $13 \mathrm{~m}$ and $17 \mathrm{~m}$ along the horizontal axis that penetrated to a depth of $130 \mathrm{~m}$ that could have been better points for the location of boreholes for groundwater exploitation. However, the existing borehole was located at $10 \mathrm{~m}$ point along the horizontal axis.

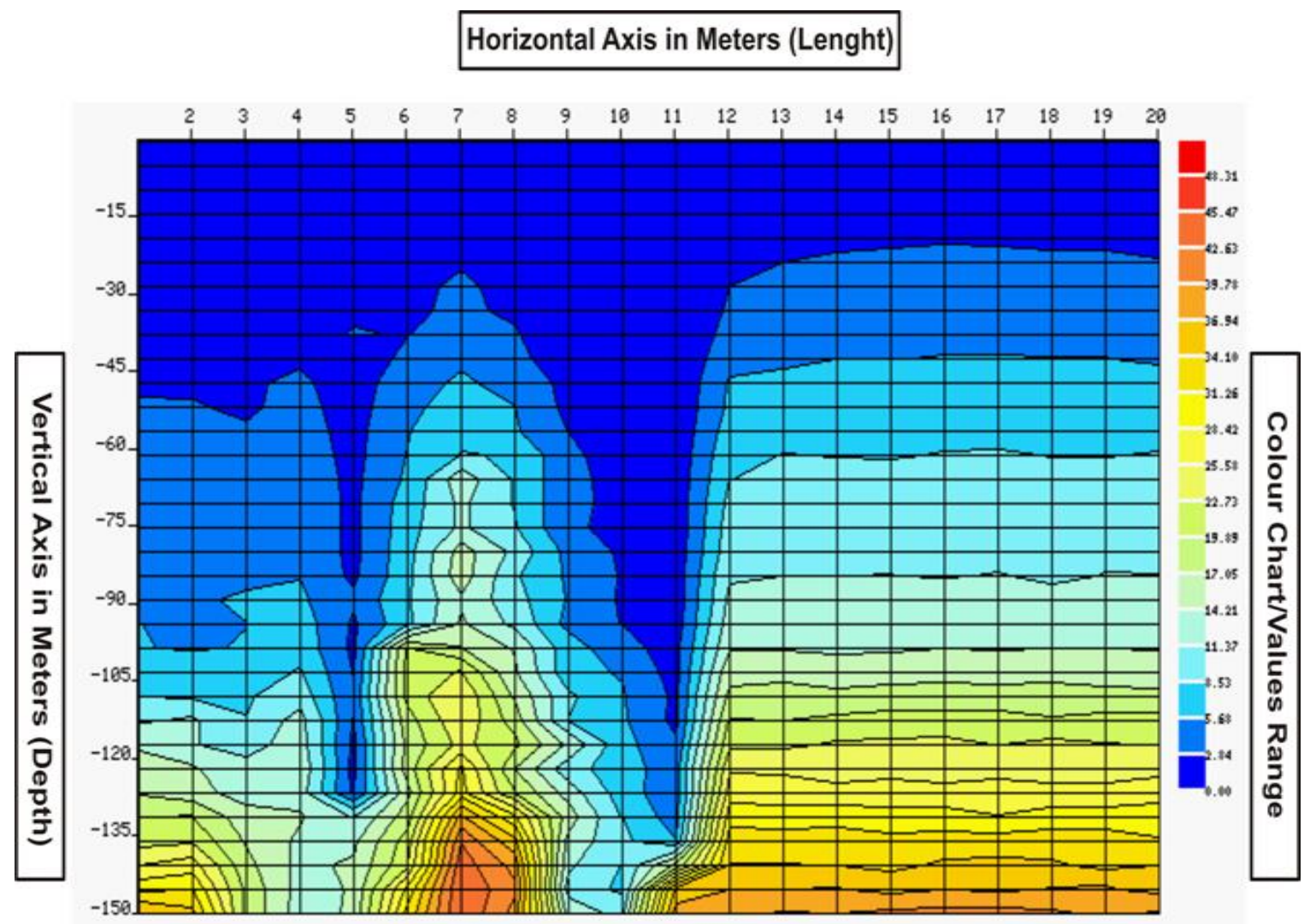

Fig. 4: Subsurface Profile Map generated from the Electromagnetic Survey carried out at the borehole along Obasanjo way (TR1) 


\section{Horizontal Axis in Meters (Lenght)}

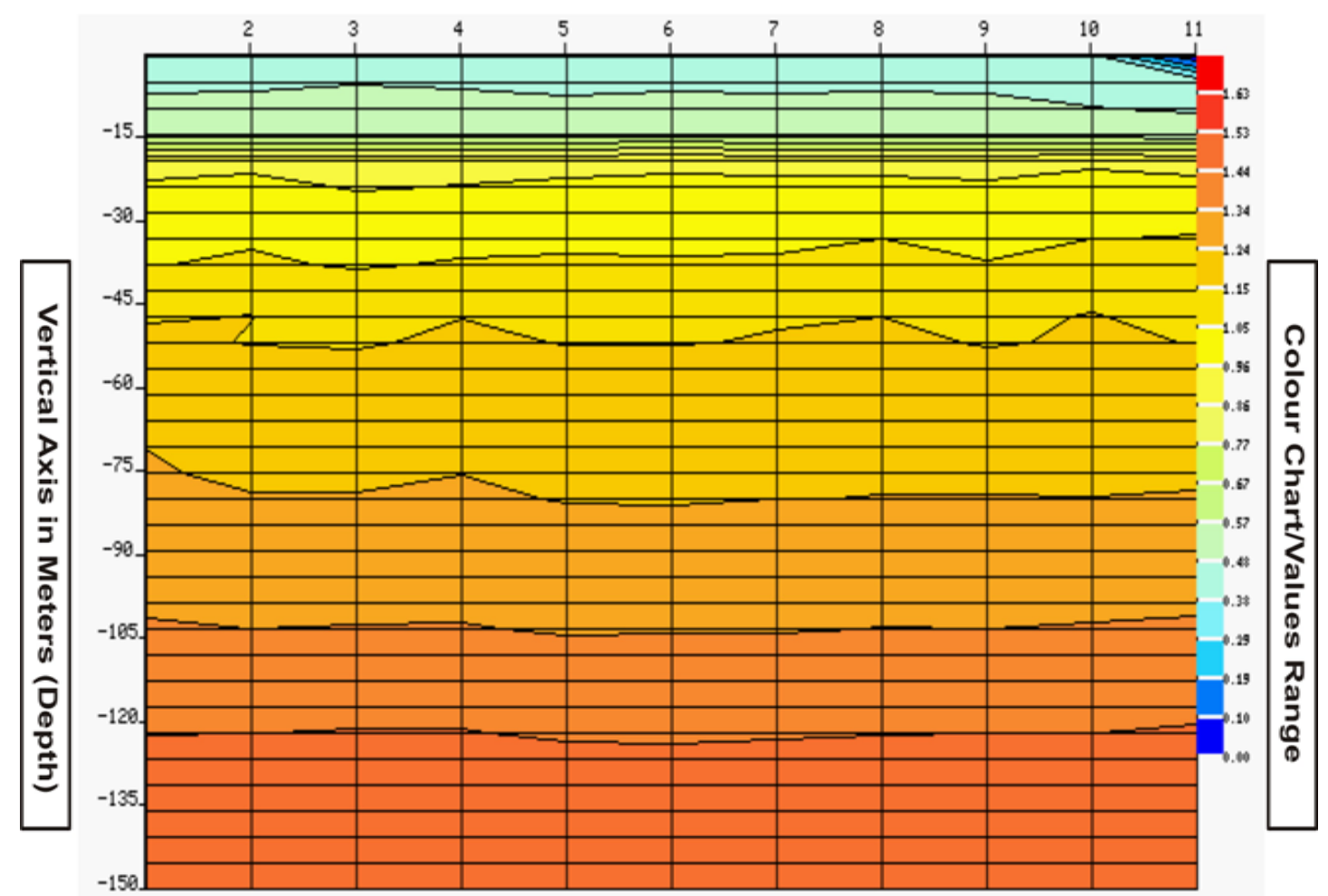

Fig. 5: Subsurface Profile Map generated from the Electromagnetic investigation of the borehole at the Local Kitchen (TR2)

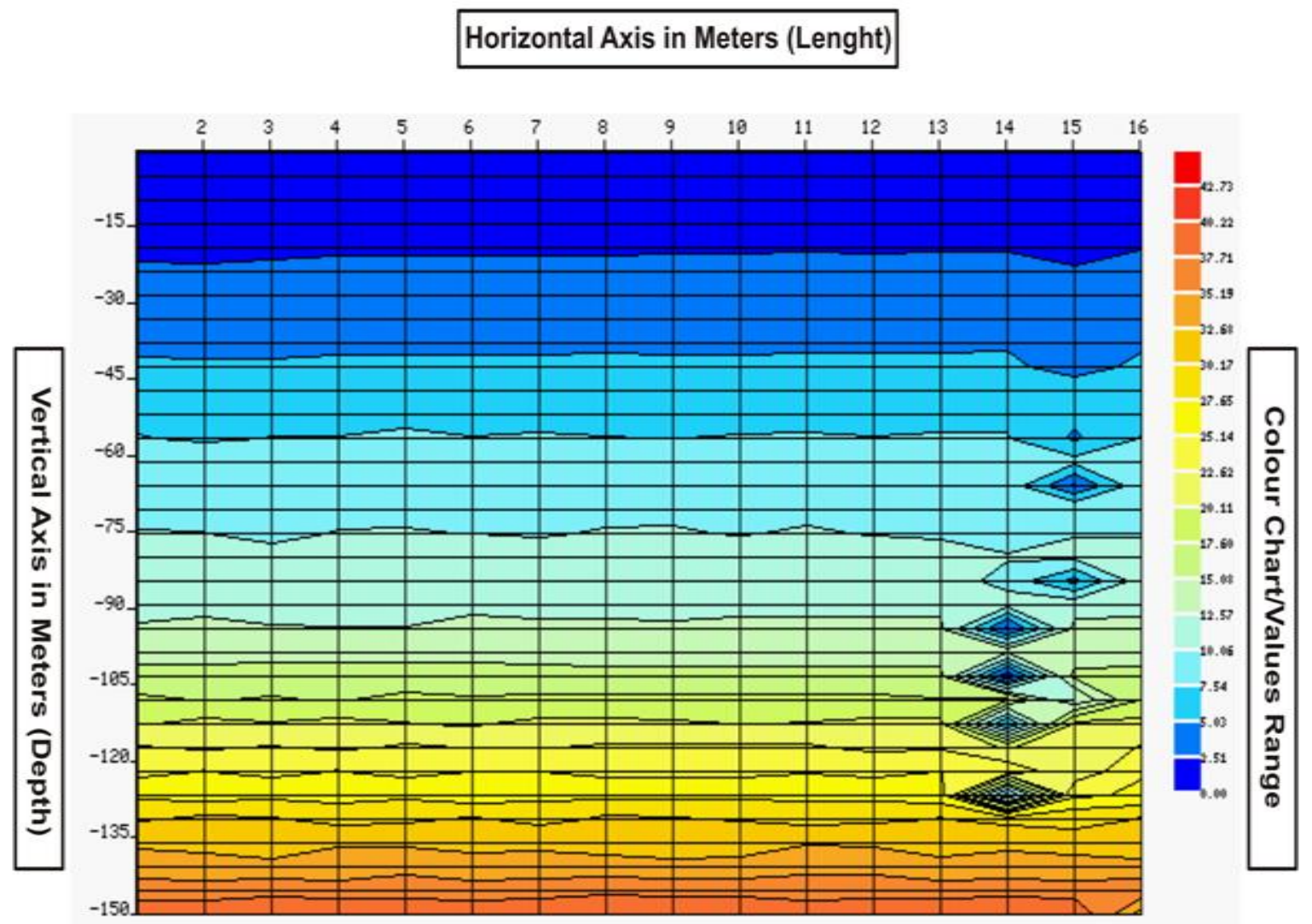

Fig. 6|: Subsurface Profile Map generated from the Electromagnetic investigation of the borehole at the Post Graduate School (TR 3) 


\section{CONCLUSION}

The failed boreholes at TR 2 was as a result of wrong siting of borehole location. There is low groundwater yield from the geological formation that cannot store or transport water in appreciable quantity; such location could at best, be used for shallow well that depends on the water table for its recharge. Location TR 4 failed due to wrong siting as well. Meanwhile, there are other areas within the same zone that could have been considered, such as the locations $13 \mathrm{~m}$ and $17 \mathrm{~m}$ along the horizontal axis. The active boreholes at TR1 was well sited in a fractured vertical point; the E.M subsurface profile map shows additional points of vertical fractures at $5 \mathrm{~m}$ and $11 \mathrm{~m}$ along the horizontal axis of measurement. This is evident in the productivity of the borehole. The productive borehole at TR 3 was also well sited in weathered zones; it was also revealed by the subsurface profile map to be an area with potentially higher groundwater extractions at points $14 \mathrm{~m}$ and $15 \mathrm{~m}$ along the horizontal axis.

From this study, we recommend that geophysical investigation/groundwater exploration be carried out with precaution. Strict adherence to the survey result should be ensured. Where it is possible, combined method of exploration should be carried out and siting of boreholes should only be in areas of good potential for sustainable groundwater supply. Electromagnetic (E.R) method for groundwater exploration should get broader acceptance due to its ease of use and requiring little or no field experience for interpretation. Its ability to generate a $2 \mathrm{D}$ image of the subsurface at a go is an added advantage for quick groundwater detection.

\section{REFERENCES}

[1]. Tom, M. S., Fischbeck, P. S. and Hendrickson, C. T. Energy use, blue water footprint, and greenhouse gas emissions for current food consumption patterns and dietary recommendations in the US. Environment Systems and Decisions, 36(1), 92-103, 2016.

[2]. Liu, J., Yang, H., Gosling, S. N., Kummu, M., Flörke, M., Pfister, S. and Alcamo, J. Water scarcity assessments in the past, present, and future. Earth's future, 5(6), 545-559, 2017.

[3]. Khalil, M. A., Abbas, A. M., Santos, F. M., Masoud, U. and Salah, H. Application of VES and TDEM techniques to investigate sea water intrusion in Sidi Abdel Rahman area, northwestern coast of Egypt. Arabian Journal of Geosciences, 6(8), 3093-3101, 2013.

[4]. Sattar, G. S., Keramat, M. and Shahid, S. Deciphering transmissivity and hydraulic conductivity of the aquifer by vertical electrical sounding (VES) experiments in Northwest Bangladesh. Applied Water Science, 6(1), 3545, 2016.

[5]. Metwaly, M., Elawadi, E., Moustafa, S. S., Al Arifi, N., El Alfy, M. and Al Zaharani, E. Groundwater contamination assessment in AlQuwy'yia area of central Saudi Arabia using transient electromagnetic and 2D electrical resistivity tomography. Environmental earth sciences, 71(2), 827-835, 2014.

[6]. Siemon, B., Christiansen, A.V. and Auken. E.A review of helicopter-borne electromagnetic methods for groundwater exploration. Near Surface Geophysics, 7(5-6), 629-646, 2009

[7]. Farquharson, C. G., Oldenburg, D. W. and Routh, P. S. Simultaneous 1D inversion of loop-loop electromagnetic data for magnetic susceptibility and electrical conductivity. Geophysics, 68(6), 1857-1869, 2003.

[8]. Delefortrie, S., Saey, T., Van De Vijver, E., De Smedt, P., Missiaen, T., Demerre, I. and Van Meirvenne, M. Frequency domain electromagnetic induction survey in the intertidal zone: Limitations of low-inductionnumber and depth of exploration. Journal of Applied Geophysics, 100, 14-22, 2014 